\title{
INVESTIGATING STATUS OF 'CORPORATE SOCIAL RESPONSIBILITY’ POLICIES AND PRACTICES: CASE STUDY OF SMALL AND MEDIUM ENTERPRISES IN JAMSHORO AND HYDERABAD DISTRICTS
}

\author{
Sarmad Aziz Pasha Khuhro1 \\ Mehran University Institute of Science, Technology and Development \\ (MUISTD), MUET, Jamshoro \\ Dr. Zahid A. Memon² \\ Mehran University Institute of Science, Technology and Development \\ (MUISTD), MUET, Jamshoro \\ Wahid Bux Mangrio 3 \\ Mehran University Institute of Science, Technology and Development \\ (MUISTD), MUET, Jamshoro \\ Irshad Aziz Khuhro4 \\ Mehran University Institute of Science, Technology and Development \\ (MUISTD), MUET, Jamshoro
}

\begin{abstract}
Purpose:- This paper is an attempt to identify corporate social responsibility practices in Small and Medium Enterprises (SMEs). It is based on the premise that most of the SMEs do not know much about the concept of corporate social responsibility as opposed to multinational enterprises. The main purpose is to look at the awareness and implementation of CSR order 2009 issued by Securities and Exchange Commission of Pakistan (SECP. The general order provides 13 areas of socially responsible businesses. Methodology/Sampling:- To conduct this baseline study a close-ended fully structured questionnaire was distributed in the SMEs located in Hyderabad and Jamshoro industrial areas. To analyzelevaluate the response, Statistical Package for Social Sciences (SPSS) is used.

Findings:- Only 39\% of the companies have information regarding CSR general order. We concluded that government should start education programs for the entrepreneurs especially for the SMEs. Communication links need be established among all the business stakeholders. The government may start incentive programs for the enterprises that are voluntarily pursuing CSR.

Practical Implications:- This research provides a basic understanding and knowhow about CSR in SMEs to do businesses on ethical grounds. This will also prove to be a catalyst for the government in devising better strategies for CSR compliance through incentives rather than exercising regulatory instruments.
\end{abstract}

Keywords : Corporate Social Responsibility, Small and Medium Enterprise, CSR Order 2009, Philanthropy, Jamshoro, Hyderabad

\section{Jel Classification: D63,D60, G38}

* The material presented by the author does not necessarily portray the viewpoint of the editors and the management of the Institute of Business \& Technology (IBT)

1 Sarmad Aziz Pasha Khuhro

2 Dr. Zahid A. Memon

3 Wahid Bux Mangrio

:pasha_khuhro@yahoo.com

:zahid.memon@faculty.muet.edu.pk

4 Irshad Aziz Khuhro

wahid.mangrio@faculty.muet.edu.pk

: Irshad_khuhro@yahoo.com

(c) IBTJBS is published by the Institute of Business and Technology (IBT).

Main Ibrahim Hydri Road, Korangi Creek, Karachi-75190, Pakistan. 


\section{INTRODUCTION}

Corporate Social Responsibility (CSR) is a concept about how enterprises bring values and needs of their stakeholders i.e. investors, customers, employees, suppliers, and local communities into their business strategies. More precisely, it is all about the society as a whole. CSR covers community relationship, environmental problems, business ethics and issues of human rights, i.e. employees' welfare programs such as education and training programs along with safety measures of the workforce at workplace. Baxi and Ajith (2005) define CSR as an obligation of industry to add to sustainable economic growth, aims at creating good values of livelihood, at the same time safeguarding the success and economic development of the corporation. As stated by Rangan et al. (2012), the issue of CSR has been captioned with the names, including strategic charity, company citizenship and social duty.

In every country, there are a huge number of small and medium enterprises investing in areas like education and other welfare programs for employees and society as a whole to increase the healthy growth of the society. The number of companies practicing CSR is on the rise in recent years. However, in developing countries this trend is not much evident. This research is about the scope of CSR in Small and Medium enterprises located at Jamshoro and Hyderabad districts of Sindh, Pakistan. In Sindh, there are a numbers of SMEs. Jamshoro and Hyderabad districts have large areas named as SITE (Sindh Industrial Trading Estates) areas, which are reserved for the commercial and industrial development. SITE Hyderabad comprises of the number of companies including leather, chemicals, electric equipment and many others. SITE Hyderabad is spread over 1268 acres and it was established in 1950. While SITE Jamshoro has enterprises such as knitting, flour mills, paper mills, and chemicals. SITE Jamshoro covers an area of 1875 acres and it was established in 1962. The reasons to choose these both districts is the existence of a variety of enterprises in the form of clusters, working in close proximities, which incite the competition of firms to create better products and unique social image.

Pakistan is focusing to build regulatory environment for the implementation of CSR. As a result, 'corporate social responsibility General Order 2009' was issued by SECP and is perceived to be one of the major steps taken by the country. This order mentioned number of fields as important and well-known CSR practices that are commonly practiced by the corporations globally. These are:

- $\quad$ Corporate philanthropy
- $\quad$ Energy conservation
- $\quad$ Community investment and welfare schemes
- $\quad$ Welfare spendection measures
- $\quad$ Industrial relations
- $\quad$ Occuployment of special persons
Business ethics and anti-corruption measures 
Investigating Status of 'Corporate Social Responsibility' Policies and Practices: Case Study of Small and Medium Enterprises in Jamshoro and Hyderabad Districts

- $\quad$ National-cause donations

- $\quad$ Contribution to national exchequer

- $\quad$ Rural development programs

This research focuses on CSR General Order 2009. The major aim is to evaluate the level of corporate social responsibility in the Small and Medium enterprises. However, to evaluate the impact of this order, the companies of Jamshoro and Hyderabad are selected as a case. This research has three objectives:

1. To evaluate the level of practice of corporate social responsibility based on General Order 2009 issued by company law division Securities and Exchange Commission of Pakistan (SECP).

2. To identify the impediments in the adoption of CSR order 2009. 3. To look into the potential benefits that CSR offers and the extent to which these benefits are recognized by the companies.

In the sections to follow, first of all literature review is discussed. Then, research methods used and data analysis is presented. Results and discussion section is given thereafter. Finally, conclusion and recommendations for future are presented.

\section{LITERATURE REVIEW}

There is an enormous amount of research regarding corporate social responsibility and economic performance of firms Carroll $(1979 ; 1991)$. CSR is all about giving financial incentives to the masses as well as company Waddock and Graves (1997). The research results of Ruf et al. (2001) mentioned that these kinds of strategies are directly concerned with the amount of sales and economic growth. In addition, the authors provide the various frameworks for corporate social responsibility. CSR is all about the scope of the firm's social benefits Davis (1973). Orlitzky.et al (2003) discussed the importance in the literature regarding its analytical evidence that there is a positive effect of CSR on the social values and it leads to the financial benefits for the firms which practice it. However, Barney and Mackey (2005) characterized the impacts with the demand and production model and with these models they have argued that socially and ethically responsible businesses have more production as well as demand for their products increases as enterprises are reliable and trustworthy in the local and international market. This all would count in the socially responsible strategies of firms. However, in all of these aspects of the business, the size of the firm does not matter. Multinationals as well small and medium enterprises are able to implement same kind of practices in the enterprise. It is also beneficial for public and healthy growth of the environment Waheed (2005). Gautam and Singh (2010) argue that the enterprises today are accepting this responsibility for the sake of their role in the society and they inform that businesses should invest in the social and environmental activities in the areas in which they are working. Now it is very much needed that there should be a strategic plan and implementation of those plans on time, so that CSR would grow and give its benefits to the society, such as sustainable environment, social and financial plans to ease the people, customers, and employees. However, CSR is not only for the help of community, but it is also equally beneficial for the companies. Kanji and Chopra (2010) point out 
that the model of triple bottom line perspective of the enterprise shows that it is beneficial for all of its major stakeholders. It is commonly known as the model of triple bottomline as shown in figure 1

Financial stability is the first choice for all businesses to survive and continue their business activities. However, it needs then to adopt CSR voluntarily in its own interest. CSR includes four prospects for the enterprises i.e. (1) the financial liability to be costeffective, (2) the legal liability to stand for the laws of the social order, (3) the moral liability to do which is a right way in a fair manner (4) the philanthropic liability to be a better corporation that contributes in societal, informative, and cultural aspects. Waheed and Shah (2008) argue that new trade policies (National and international), legislation (CSR General order of 2009), changing international trends, demands, and business driven social investments indicate an emerging emphasis on corporate citizenship in Pakistan. This reflects that the society is evolving and customers are demanding for the responsible businesses. This phenomenon can also be witnessed into the academia of Pakistan, as they are imparting education related to responsible businesses in the business and management schools. Memon et.al (2014) writes that the field of CSR is emerging as a future academic discipline in the business and management schools of Pakistan. Writer further argues that the Universities are the most important actors in strengthening CSR culture and values in the Pakistan.

\section{METHODS}

To observe the impact of CSR order 2009, we surveyed those SMEs of Jamshoro and Hyderabad districts which are registered with SMEDA (Small and Medium Enterprise Development Authority). We designed and circulated close-ended questionnaires that included all the fields of CSR that are mentioned in the general order. The questionnaire was posted and delivered to companies' mailing addresses. Most of the questions were close ended. The returned questionnaires were analyzed in Microsoft excel and SPSS, t-test and frequency tests were applied.

Quantitative methodology was used to conduct this research, because it is used extensively in business and other economic researches. Quantitative methodology can portray results in much better way by using graphs and charts. As it is easy to express results and can be understood by the readers after reviewing the charts or graphs. Questions were also asked from management of the companies. Response rate initially stood at $88 \%$ from companies of both districts together but some of those companies i.e. $6 \%$ filled questionnaires improperly, therefore, these were discarded. Respondents of this research are the authorities of the companies. Most of the companies, which answered to the questionnaire, were leather, knitting, polymer, electric equipment manufactures and furniture industries. The questionnaire was designed for general industrial sectors. 


\section{RESULTS AND DISCUSSION}

The questionnaire was designed as per the corporate social responsibility General Order 2009. A major part of the questionnaire enquired from the respondents about implementation of General Order 2009 principles in their industries. The questionnaire comprised of 27 questions, which were divided into two parts:

i. Information of company

ii. Questions related to the CSR practices in company

The first question of second part (Questions related to the CSR practices in company) was that does company have any knowledge about CSR. The reply stood as shown in figure 2. Fifty-seven percent (57\%) of companies have knowledge and the forty-three $(43 \%)$ of companies were devoid from the concept of CSR.(See Figure 2)

The second question pertained to whether government (registration authorities) has ever communicated to company regarding CSR. Eighty-two (82\%) of respondents denied regarding any knowledge communicated from the government or concerned authorities as depicted in figure 3

McWilliams and Siegel (2006) state that the stakeholders including community, employees and government have major role to play for the CSR practices. Albareda et al. (2008) mentioned that in Norway, the Ministry of the Environment is working to implement CSR objectives in their sustainable program preferences. Pascal (2002) in his research found that the governmental steps are very important for creating the ground for the private sector to start working on CSR. The government helps the firms by creating awareness regarding CSR. However, unfortunately concerned authorities in Pakistan have been ignoring this important business strategy, which can potentially lead the firms to get competitive advantages in the international market.

The first CSR strategy in CSR General order 2009 is Philanthropy, question no 5 investigated company about the Philanthropic work done by company.The reply of companies reveal that twenty five percent $(25 \%)$ have initiated philanthropic work after issuance of CSR general order 2009. As shown in figure 4. Porter and Kramer (2006) argue that philanthropic functions are closely related with the enterprises operation preferences, as it is a good initiative to work for the betterment of the people. (See Figure 4)

The second CSR principle in general order 2009 is energy conservation. The results reveal that thirty-six percent (36\%) companies are adopting energy conservation strategies. Rathi et al. (2012) state that Pakistan's Industrial sector is the biggest consumer of energy, but it accumulated only 19\% GDP in the FY 2008 (ADB) due to inefficient technology and crumbling of infrastructure. Therefore, energy conservation 
stood high in practice for the CSR in the country and round the world. Thirdly, Environmental protection is mentioned as a major CSR principle in general order 2009. Thirty-six percent $(36 \%)$ of companies have taken certain steps to reduce their part in global warming. 64\% of companies in Hyderabad and Jamshoro district are not taking any measures to reduce the air pollution. These are not implementing any policies that could help country reduce pollution. However, it is noticed that workforce of such industrial areas and close proximity is effected by the emission of these companies.

We included a question to gain an understanding on investment on the welfare schemes by the companies. The questionnaire investigated that if companies are making any investments in the welfare schemes for local community. The respondents have revealed that no any company from selected sample has invested in the schemes related to welfare of local inhabitants. In Pakistan the consumer rights commission is working and providing help to the community regarding all the matters of exploitation as per guidelines of United Nations customer right protection bill of 1985. Therefore, consumer protection measures mentioned in general order 2009 were also investigated. It was found that no any company has taken steps for consumer protection measures. AbefeBalogun, and Bolaji (2011) presented in their research that the people or the organizations belonging to wealthy and well settled owners should help those people of the community that are not as wealthier and need to get help from other parts of society. With regard to welfare for underprivileged class, a question was also posed to companies. We found that no any company from the selected sample has any policy regarding welfare for underprivileged class.

The CSR general order 2009 indicates that the industrial relations are significant for growth of a company revenue and are indirectly beneficial for the stakeholders. This was validated, as shown in figure 4 that forty-six percent (46\%) companies have created cooperation and joint ventures with other local industries because of issuance of CSR general order 2009.

According to Adedipe and Babalola (2014), firms are probably responsible in the sections of creating jobs and economic opportunities for both physically fit and the disabled persons. The issue pertaining to vacancies for the physically challenged persons is also part of the CSR guidelines issued to the companies by SECP. The question was asked whether company has reserved vacancies for special persons. In reply, only twenty four percent (24\%) of companies surveyed responded in positive by informing that these have reserved vacancies for the special persons. Occupational safety principle, mentioned in CSR general order 2009 was also investigated in this research study. It was found that eighty-nine percent (89\%) companies have provided occupational safety to the employees in case of any accident or misshape. Greg Hills (2009) argue that corporations should also build a compliance program for the reduction of the corruption and effect of corruption. Respondents were, hence, enquired about the business ethics and anti-corruption measures. Results elucidate that forty-three percent (43\%) companies (as shown in figure 4) have policies regarding business ethics and anti-corruption measures. Whereas, some firms are taking measures to prevent corruption only.

Eleventh issue in the CSR order relates to whether company is spending on national 
cause. It was found that only eighteen percent (18\%) of companies are spending on donations. However, $82 \%$ of companies do not have any information regarding CSR strategy and principles pertaining to this particular issue. In response to contribution to national exchequer, it was found that thirty-nine $(39 \%)$ percent of the companies are contributing in national exchequer through different ways. Moseley and Malcolm J. (2003) write that, rural development should be given more importance in social responsible practices. However, all of the small and medium enterprises of the sample are ignorant to this practice. Lastly, regarding contribution to the rural development programs, results revealed that all the organizations are devoid of this responsibility as none of the companies is contributing for the rural development programs. T-test was applied to check the implementation of principles of CSR in the companies and it was found that most of the principles have not been implemented as the mean value for "yes" for all the questions about CSR principles is found to be 3.879 and the t-test value is 3.879 (See Table 1)

Consequent upon issuance of CSR order, only eighteen percent of the SMEs in the industrial zones of these two districts have adopted these principles in partial compliance to it. In order to explore the effectiveness of the CSR order, we surveyed whether the general order of 2009 is a comprehensive guiding document or not. A considerable number of SMEs, as shown in figure 5 suggested that it is complete, comprehensive, and effective if implemented. (See Figure 5)

McWilliams and Siegel (2006) argue that, all the shareholders especially owners and government have major role to play in the CSR. The major responsibility lies with the both company and the government to make the SME sector behave ethically. The reasons for not adopting CSR order have also been identified as in the figure 6 below. (See Figure 6)

Forty-six percent SMEs (46\%) answered that they lack in resources to start adopting CSR practices, $31 \%$ of companies assumed that corporate social responsibility is only the duty of the public organizations, $15 \%$ of respondents, however, were unwilling to adopt CSR practices whereas eight percent (8\%) companies found CSR as an obstructive strategy for the company.

With regard to potential benefits that CSR offers, we looked into the company perspective as a result of adopting CSR order. We included three issues pertaining to CSR related certification, profit margins and social image in our survey. In addition to that, pressure from customers as a catalyst to pursue CSR, was also made part of the investigation. (See Figure 7)

As per global trend, corporate sector adopts CSR mostly on the customer demand; similar trends were witnessed during the survey. As depicted in figure 7, forty three percent $(43 \%)$ of companies indicated to adopt CSR on customer demand. Remaining $57 \%$ were a bit confused or reluctant to adopt CSR even if pressure is exerted from the buyers of their product. 
CSR as ISO certified protocol was approved in 2010 under ISO-26000:2010. ISO 26000 is a set of guiding principles that help organization understand and behave responsibly. This protocol informs organization about the expected principles for running the business. The question was asked from the selected companies that whether ISO certification would raise company's rating. The results shown in the figure 7 revealed that thirty-six percent (36\%) percent companies responded that ISO protocol and its certification is helpful for the escalation of company's rating.

Tyagi (2012) writes that CSR has come out as an aspect that it can also increase the financial performance as better image of the company will increase its sales revenue due to reliable products having more demand. Furthermore, Costa and John (1998) argue that CSR notions were being applied since long in many developed countries, resultantly the quality and productivity has been improved. Waheed (2005) mentioned that many of the neighboring countries of Pakistan are gaining competitive advantage, especially Sri Lanka by using the sustainable development as major strategy to gain recognition in the international market. Figure 7 shows that sixty-eight percent $(68 \%)$ companies of selected sample also agreed that benefits that CSR brings are enormous. CSR is helpful to increase company's social and ethical image that will help to increase company's profit in the market. In this regard the companies were asked about the effect of CSR on the company's better image and profit margin. Only fourteen percent $(14 \%)$ of the companies agreed that CSR has an impact, whereas, $86 \%$ denied this implication.

\section{CONCLUSION}

Corporate Social Responsibility (CSR) is a new but emerging concept for the healthy practices in the corporate world. CSR General Order 2009, issued by the Securities and Exchange Commission of Pakistan (SECP), is a fundamental step to ensure the awareness and implementation of CSR in Pakistan. This research article evaluates the impact of the order on the small and medium enterprises located in Jamshoro and Hyderabad District of Sindh, Pakistan. After reviewing the results, it was found that most of the Small and Medium Enterprises (SMEs) working in Jamshoro and Hyderabad Districts do not have much knowledge about CSR.

It was found that business firms and concerned authorities were direly lacking in information and seriousness towards CSR. Only 39\% of the companies have knowledge about CSR general order. Of the thirteen CSR issues raised in the CSR order 2009, the SMEs were deficient in almost every principle except the workplace safety measures. This abysmal situation is due to the lack of communication and implementation. CSR strategies and policies need long term and persistent efforts to get benefit from that CSR offers to companies.

CSR is an underexploited and ignored area by both SMEs and the government. Companies have not yet even recognized the worth of The General order 2009. This is because of the lack of education, information and poor communication. $79 \%$ of organizations agreed that the implementation of CSR would be easy with government's 
Investigating Status of 'Corporate Social Responsibility' Policies and Practices: Case Study of Small and Medium Enterprises in Jamshoro and Hyderabad Districts

power of coercion. $43 \%$ of companies are ready to adopt CSR in case of customer demand. This, however, indicates that CSR may gain acceptance in future.

\section{RECOMMENDATIONS}

Following are the few suggestions/recommendations extracted from the literature and survey.

1. Government should start education programs for the entrepreneurs of every size of the company but especially for the SMEs, as they are lacking awareness about international market demands. Therefore, they may need to acquire relevant knowledge of the business ethics and CSR.

2. Awareness programs for the public will increase the demand of CSR as well, such as healthy practices at workplace, and occupational safety.

3.) Develop the cooperation amongst the shareholders about encouraging CSR policies which needs to be discussed and implemented with the agreement of all stakeholders.

4.) Awareness programs for the SMEs regarding the business ethics and for the practical approaches to the enterprises as it would help the enterprises good reputation in the business world and will lead to increase in the profit margin.

\section{ACKNOWLEDGEMENT}

First of all with a profound gratitude, we are thankful to Almighty Allah forgiving us success, knowledge and understanding without which we would not been capable of completing this research paper.

We are also profoundly grateful to all our family members whose endurance and understanding have played a significant role in our success by sacrificing the important family time and supporting us all over the research work.

We are finally thankful to the editor, reviewers and IBT specially who provided us with the opportunity to publish our research paper in this esteemed journal.

\section{REFERENCES}

Abefe-Balogun, Bolaji (2011) "problem and prospect of corporate social responsibility in national development" Continental Journal of Sustainable Development,2 (2), $19-25$.

Adedipe, O. A., \&Babalola, A. (2014). Corporate Social Responsibility: Panacea to Corporate Growth. Journal of Economics and Sustainable Development, 5(12), 29-39.

Albareda, L. Lozano, J. M, Tencati. A, Midttun. A (2008).The changing role of governments in corporate social responsibility: drivers and responses. Business Ethics: A European Review. pp.347-363.

Baxi, C V \& Prasad Ajit (2005), 'Corporate Social Responsibility-Concept and Cases, Excell Books, New Delhi'.

Barney, J. B., \& Mackey, T. B. (2005). Testing resource-based theory. Research methodology in strategy and management, 2, pp. 1-13. 
Carroll, A. B. (1991). The pyramid of corporate social responsibility: Toward the moral management of organizational stakeholders. Business horizons, (34), 39-48.

Costa.D, .John (1998), The ethical imperative, Harper Collins (1998)Toronto

Davis, K. (1973). The case for and against business assumption of social responsibilities. Academy of Management journal, 16(2), pp.312-322.

Gautam, R.,Singh, A. (2010). Corporate social responsibility practices in India: a study of top 500 companies. Global Business and Management Research: An International Journal, 2(1),pp. 41-56.

Hills, G., Fiske, L., \& Mahmud, A. (2009). Anti-corruption as Strategic CSR: A call to action for corporations. FSG Social Impact Advisors.

Kanji, G. K., \& Chopra, P. K. (2010). Corporate Social Responsibility in a Global Economy. Total Quality Management, 21(2),pp.119-143.

Lamy, Pascal. (2002) 'Stepping stones or stumbling blocks? The EU's approach towards the problem of multilateralism vs regionalism in trade policy. The World Economy.pp.1399-1413.

McWilliams, A., Siegel, D. S., \& Wright, P. M. (2006). Corporate social responsibility: Strategic implications. Journal of management studies, 43(1),pp. 1-18.

Memon, Z. A., Wei, Y. M., Robson, M. G., \& Khattak, M. A. O. (2014) Keeping track of 'corporate social responsibility 'as a business and management discipline: case of Pakistan. Journal of Cleaner Production, 74, pp. 27-34. Moseley, Malcolm. J, (2003) 'Local partnerships for rural development: the European experience'. CABI, Wallingford, Oxon, UK.

Orlitzky, M., Schmidt, F. L., \&Rynes, S. L. (2003). Corporate social and financial performance: A meta-analysis. Organization studies, 24(3), pp 403-441.

Porter, M. E., \& Kramer, M. R. (2006). The link between competitive advantage and corporate social responsibility. Harvard business review, 84(12), pp 78-92.

Rangan, K., Chase, L. A., \& Karim, S. (2012). Why every company needs a CSR strategy and how to build it.

Rathi, M., Shaikh. P. H., Shaikh. F., \& Uqailli, M. A. (2012). Energy Conservation through Motors in Pakistan's Industrial Sector-Need to Use of Energy Efficient Motors. Energy Conservation, 54(5).

Ruf, B. M., Muralidhar, K., Brown, R. M., Janney, J. J., \& Paul, K. (2001). An empirical investigation of the relationship between change in corporate social performance and financial performance: A stakeholder theory perspective. Journal of Business Ethics, 32(2),pp 143-156.

Tyagi, R. (2012).Ph. D Thesis: Impact of Corporate Social Responsibility on Financial Performance and Competitiveness of Business: A Study of Indian Firms.

Waddock, S. A., \& Graves, S. B. (1997). The corporate social performance-financial performance link. Strategic management journal, 18(4), pp.303-319.

Waheed, A. (2005).Security and Exchange Commission of Pakistan and United Nations Development Programs'

Waheed, A. Shah, F.(2008) .Mainstreaming Corporate Citizenship andResponsible Business Principles into Corporate Policy,Responsible Business InitiativeJune 2008 www.RBIpk.com (concept paper) 
Investigating Status of 'Corporate Social Responsibility' Policies and Practices: Case Study of Small and Medium Enterprises in Jamshoro and Hyderabad Districts

\section{APPENDIX (Figures and Tables)}

Figure 1 Model of Triple Bottom line Perspective. Source: Google images (2013)

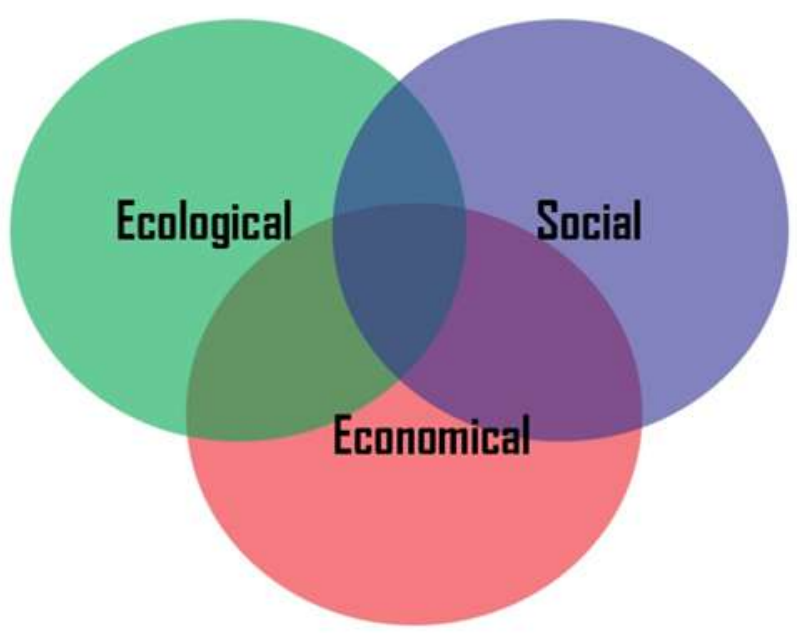

Figure 2 Knowledge regarding CSR

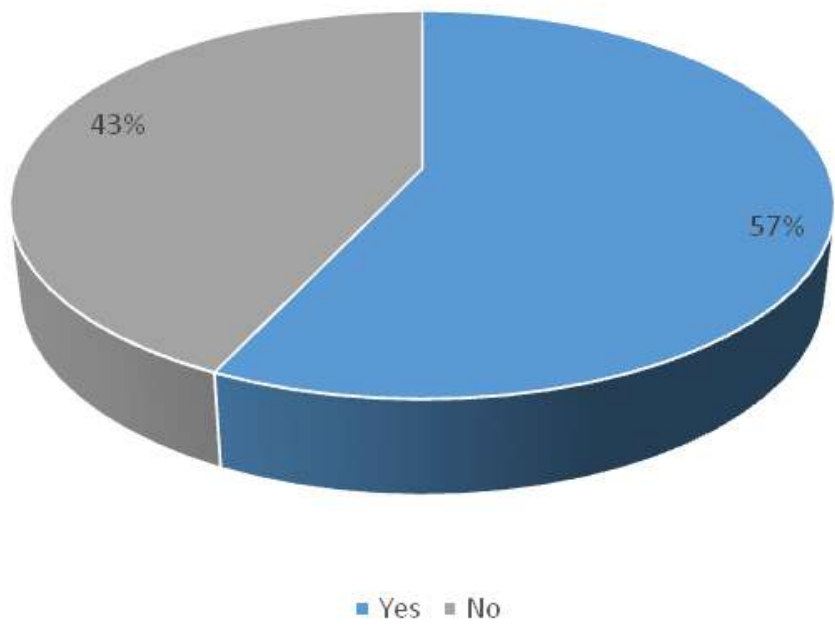



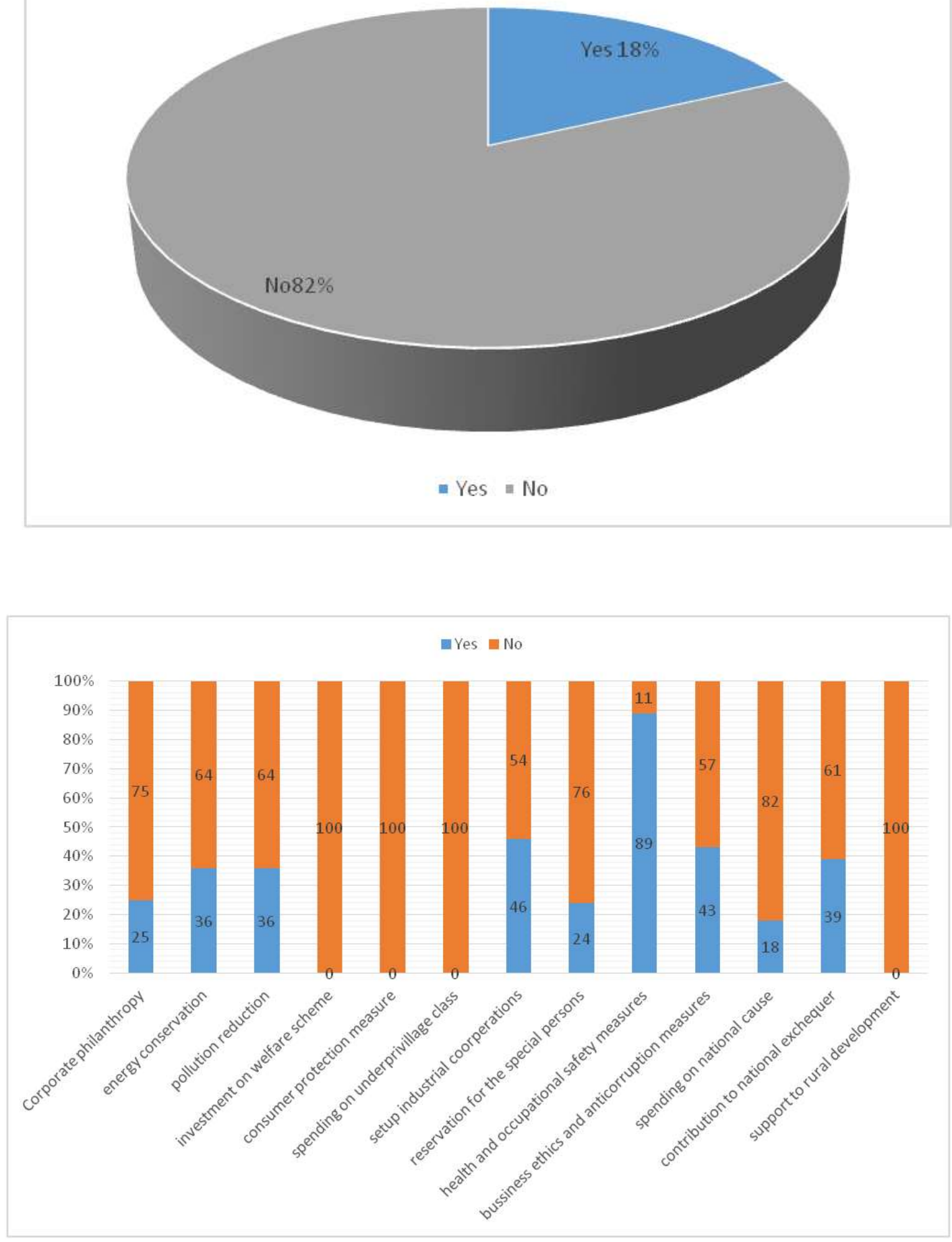

Vol. 11, No. 2, (Fall2015) 
Investigating Status of 'Corporate Social Responsibility' Policies and Practices: Case Study of Small and Medium Enterprises in Jamshoro and Hyderabad Districts

\begin{tabular}{|l|r|r|r|r|r|r|}
\hline & \multicolumn{9}{|c|}{ Teat Value = 0} \\
\cline { 2 - 6 } & $\mathrm{t}$ & Df & Sig. (2-talled) & Mean Difference & $\begin{array}{r}\text { 95\% Confidence Interval of the } \\
\text { Difference }\end{array}$ \\
& & & & & Upper \\
\hline YES & 3.879 & 12 & .002 & 27.38462 & 12.0027 & 42.7665 \\
NO & 10.286 & 12 & .000 & 72.61538 & 57.2335 & 87.9973 \\
\hline
\end{tabular}

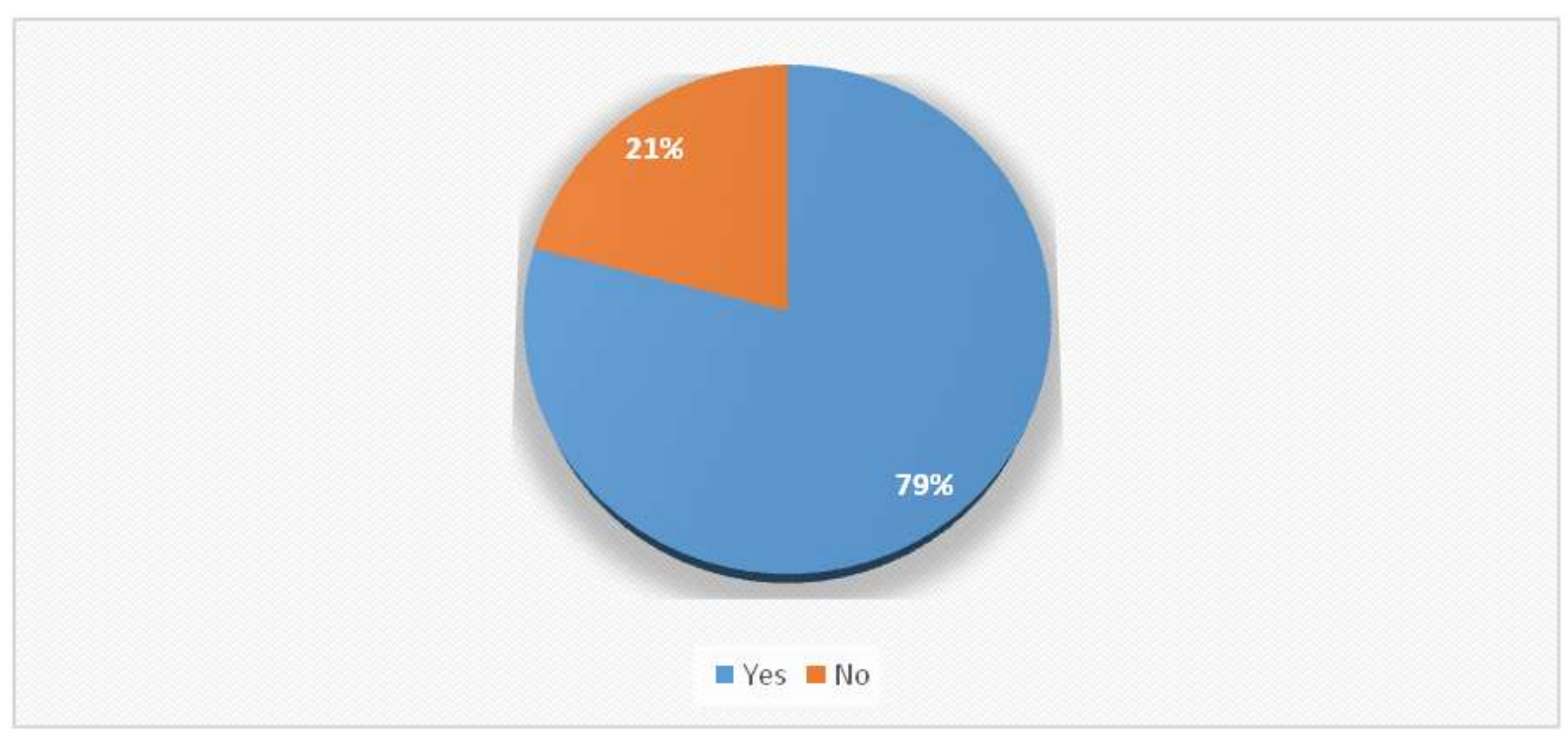



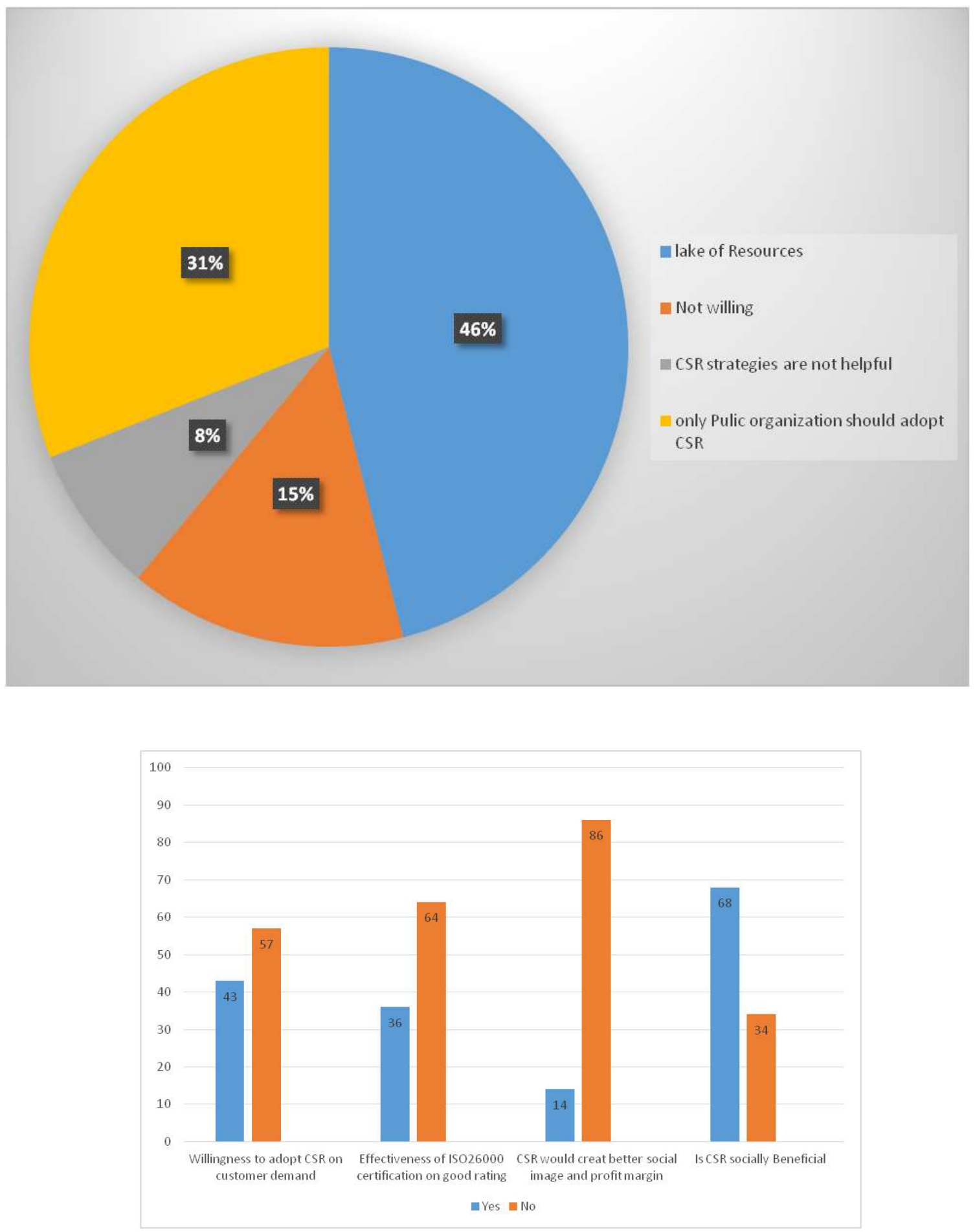

Vol. 11, No. 2, (Fall2015) 